\title{
ESPECIALIZAÇÃO EM ENFERMAGEM DO TRABALHO: Uma Proposta de Mudança de Paradigma
}

\section{LABOUR NURSING SPECIALISATION: A Proposal of Paradigm Change ESPECIALIZACIÓN EN ENFERMERÍA DEL TRABAJO: Una propuesta de Cambio de Paradigma}

Maria Yvone Chaves Mauro ${ }^{1}$

\begin{abstract}
RESUMO: O Curso de Enfermagem do Trabalho teve como objetivo preparar enfermeiros em segurança e saúde do trabalhador para empresas. Iniciou-se em 1974, como resultado da luta do DESP/EEAN/UFRJ e da ABEn, junto ao Ministério do Trabalho no Rio de Janeiro, e baseando-se na Resolução 112/59 - OMS/OIT. Posteriormente, o curso foi difundido para outras Universidades e Regiões do País, tendo sido realizados 13 cursos até 1985. No início, os cursos seguiram orientação e controle da FUNDACENTRO, até 1996, e eram voltados para a indústria. A partir desta data, o registro destes cursos passaram para os CORENs e realizados independentemente nas Escolas de Enfermagem, com base na Resoluçāo 12/86 MEC, Rec. 161/93 - OIT, Diretrizes do Ministério do Trabalho e Ministério da Saúde. Na EEAN, até 1995, foram realizados 11 Cursos de Especialização, apoiados na orientação da ANENT e fundamentados pelas disciplinas: Metodologia da Investigação Científica: Metodologia do Ensinamento de Enfermagem e Educação para a Saúde; Políticas de Saúde do Trabalhador; Ciências Sociais e Organizacionais do Trabalho: Saneamento do Meio Ambiente: Higiene e Segurança do Trabalho e Ecologia Humana, Ergonomia, Processo de Trabalho; Riscos Ocupacionais: Enfermidades e Acidentes de Trabalho: Legislação do Trabalho. Enfermagem do Trabalho. Visitas Técnicas e Práticas nos Serviços de Saúde do Trabalhador nos Programas de Empresas e de Saúde Pública. O curso capacita enfermeiros para atividades assistenciais, educativas, gerenciais e de investigação e sua formação culmina com uma dissertação tendo como objetivo de estudo problemas emergentes da prática de Enfermagem junto ao Trabalhador. Este programa tem sido estudado pela própria autora visando a melhor adequação da inserção desses profissionais no mercado de trabalho.
\end{abstract}

PALAVRAS-CHAVE: Especialização - Enfermagem do trabalho - Formação - História da enfermagem.

\footnotetext{
Profa. Titular de Enfermagem de Saúde Pública na Faculdade de Enfermagem da UERJ. Presidente da Associação Nacional de Enfermeiros do Trabalho - Seção RJ. Docente Livre e Doutora em Enfermagem pela UFRJ. Especialista em Saúde Pública, em Enfermagem do Trabalho e em Educação na Área da Saúde pela UFRJ. Redatora da Revista Enfermagem - UERJ.
} 
ABSTRACT: The course of Labour Nursing aimed at preparing nurses for companies security and workers health. It started in 1974 as a result of the efforts of DESP/EEAN/UFRJ and ABEn close to the Ministry of Labour in Rio de Janeiro and based on the Resolution 112/59 - OMS/OIT. Later, this course was spreaded out to other Universities and Brazil's regions and 13 courses have been provided until 1985. In the beginning, the courses follwed the orientation and control of FUNDACENTRO. until 1996 and were directed to the industry. From this time on, these courses register was sent to CORENs and accomplished independently at Nursing Schools, based on Resolution 12/86 - MEC, Rec. 161/93 - OIT, Instructions from the Ministry of Labour and Ministry of Health. At the EEAN, up to 1995. 11 Specialisation Courses have been accomplished, based on ANENT orientations and fundamented by the subjects: Scientific Investigation Methodology. Methodology of Nursing Teaching and Education for Health: Worker's Health Politics; Labour Organisational and Social Sciences; Environment Sanitation; Work Safety and Hygiene and Human Ecology: Ergonomy; Labour Process; Occupational Risks; Labour Accidents and IIInesses; Labour Legislation; Labour Nursing; Technical Visits and Practice in Workers Health Services at Companies Programmes and Public Health. The couse enables nurses of assistential, educative, managering and investigative activities and their formation culminates with a dissertation that has as a study object, emerging problems of nursign practice for workers. This programme has been sutdied by the author herself aiming at a better adjustment for these professionals insertion into the work market.

KEYWORDS: Specialization - Labour nursing - Formation - History of nursing. 
RESUMEN: El curso de Enfermería del Trabajo tuvo como objetivo preparar Enfermeros en seguridad y salud del trabajador para empresas. Se inició en 1974 , como resultado de la lucha del DESP/EEAN/UFRJ y de la ABEn, junto al Ministério del trabajo en Rio de Janeiro, teniendo como base la resolución 112/59 - OMS/OIT. Posteriormente, el curso fué defundido para outra Universidades y Regiones del País, permitiendo com eso que fueran realizados 13 cursos hasta 1995. En el início, los cursos acompañaron orientación y control de la FUNDACENTRO, hasta 1996, y eran destinados para la industria. Desde esta fecha, el registro de estos cursos fué repasado a los CORENs y realizados independientemente en las escuelas de Enfermería, teniendo como base la resolución 12/86 - MEC, Rec. 161/93 - OIT, directrizes del Ministério del Trabajo y Ministério de la Salud. En la EEAN, hasta 1995. fueron realizados 11 cursos de Especialización, apoiados en la orientación de la ANENT y fundamentados por las diciplinas: Metodologia de la Investigación Científica; Metodologia de la enseñanza de Enfermeriay Educación para la Salud; Políticas de Salud del Trabajador; Ciencias Sociales y Organizacionales del Trabajo; Saneamiento del Medio Ambiente; Higiéne y Seguridad del Trabajo y Ecología Humana, Ergonomia, Proceso del Trabajo; Riesgos Ocupacionales; Enfermidades y Accidentes de Trabajo; Legislación del Trabajo, Enfermería del Trabajo, Visitas Técnicas y prácticas en los servicios de Salud del Trabajador en los programas de Empresas y de Salud Pública. El curso capacita Enfermeros para actividades asistenciales, educativas, gerenciales y de investigación y su formación alcanza su punto máximo con una desertación que tiene como objeto de estúdio los problemas que se asoman de la práctica de Enfermería junto al trabajador. Este programa todavia lo esta esdudiando la propia autora con el objetivo de una mejor adecuación de introducción de estos profisionales en el mercado de trabajo.

PALABRAS CLAVES: Especialización - Enfermería del trabajo - Formación - Historia de la enfermería.

\section{INTRODUÇÃO}

O Curso de Especialização em Enfermagem do Trabalho, no Brasil, nasceu em 1974, por força da diretriz política do Ministério do Trabalho FUNDACENTRO. Seu Marco Referencial apoiou-se originariamente nas características geo-políticas do país voltado às áreas industrializadas e na situação econômica, para atender a população economicamente ativa (PEA) das médias e grandes indústrias e na situação de saúde da população trabalhadora, com ênfase nos acidentes de trabalho e nas doenças ocupacionais. Hoje, a formação do Enfermeiro do Trabalho tende a acompanhar as diretrizes das Políticas de Saúde do Trabalhador, com base na Constituição Federal Brasileira (1988) e na Lei $n^{\circ} 8.080 / 90$ - SUS. 


\section{DIRETRIZES POLÍTICAS DE SAÚDE DO TRABALHADOR}

A saúde do trabalhador, no Brasil, teve como base a Portaria $n^{\circ} 3236 / 72$, do Ministério do Trabalho, que instituiu o Programa Nacional de Valorização do Trabalhador (PNVT) com Sub-Programas, Projetos e Atividades Prioritários, estabelecendo metas para intervir no alto índice de Acidentes de Trabalho (AT) que, à época, colocava o Brasil com o maior índice de acidentes deste tipo. Neste sentido, a Meta IV do PNVT visava: "Preparar, no período de 1973-1974, 13.839 profissionais de nivel superior e médio para o controle da segurança e higiene do trabalho; promover a Campanha Nacional de Acidentes do Trabalho, com a finalidade de divulgar conhecimentos técnicos, e ministrar ensinamentos práticos de prevenção de acidentes, segurança e medicina do trabalho" (1973).

Esta determinação do Ministério visava baixar os indices de acidentes no trabalho, e teve, como referência, a Recomendação $n^{\circ} 112 / 59$ da OIT/OMS, intitulada "Recomendação para os Serviços de Saúde Ocupacional", a qual, até então, não havia sido considerada pelo governo brasileiro. Esta recomendação definiu o Serviço de Saúde Ocupacional como um Serviço Médico instalado num estabelecimento de trabalho ou em suas proximidades, com os seguintes objetivos: 1)proteger a saúde dos trabalhadores contra qualquer risco que po sa decorrer do seu trabalho ou das condições em que este é realizado; 2 ) contrib: * para o ajustamento do trabalhador através da adaptação do trabalho aos trabalhadores e pela colocação deste em atividades profissionais para as quais tenha aptidões; 3) contribuir para o estabelecimento e manutenção do mais alto grau possivel de bem-estar físico e mental dos trabalhadores. (FUNDACENTRO, 1959).

A Recomendação $n^{\circ} 112 / 59$ só produziu seus efeitos em 1972 em decorrência do período intitulado "milagre econômico" da década de 70 no Brasil, quando houve um grande afluxo de mão-de-obra não qualificada para a indústria sem as adequadas condições de trabalho correspondentes, resultando no elevado indice de acidentes de trabalho. $\mathrm{O}$ alto índice de acidentes de trabalho foi o fator político determinante para a criação da legislação de proteção à saúde dos trabalhadores nas empresas, o que deu origem às Portarias que determinaram a formação dos especialistas em Segurança, Higiene e Medicina do Trabalho. Dai a formação inicialmente ser direcionada para trabalhadores nas empresas de médio e grande porte.

O Ministério do Trabalho, com base nestas considerações e no PNVT, subsidiou através da FUNDACENTRO a formação de Médicos, Engenheiros e Supervisores de Segurança e Auxiliares de Enfermagem do Trabalho, omitindo o Enfermeiro do Trabalho, conforme a Portaria $n^{\circ} 3237 / 72$ que definiu o dimensionamento do serviço e da equipe em relação ao número de empregados na empresa: 01 Médico a partir de 101 empregados; 01 Auxiliar de Enfermagem a partir de 501 empregados; 01 Engenheiro de Segurança a partir de 101 empregados e 01 Supervisor de Segurança a partir 50 empregados. 
A publicação desta Portaria foi denunciada pela Escola de Enfermagem Anna Nery / EEAN - UFRJ, em conjunto com a Associação Brasileira de Enfermagem, o que se tornou um desafio para os enfermeiros, começando uma luta para a modificação da Portaria, no sentido de incluir o Enfermeiro na Equipe de Saúde Ocupacional. O curso de Especialização em Enfermagem do Trabalho foi o instrumento. Assim, foi travada uma luta paralela para o reconhecimento, pelo Ministério do Trabalho, do curso que estava sendo realizado pela EEAN da Universidade Federal do Rio de Janeiro, em 1974. A primeira turma formou 38 alunos, evidenciando um atraso de 20 anos em relação ao inicio do ensino da Medicina do Trabalho no Brasil.

Em 1975, ao concluir a $2^{\mathrm{a}}$ turma (da qual fez parte esta autora), conseguiu-se o reconhecimento do Curso pelo Ministério do Trabalho, e a promulgação da Portaria $n^{\circ} 3460$ de 31/12/75, com a inclusão do Enfermeiro na Equipe de Saúde Ocupacional, na proporção de 01 Enfermeiro para empresas com o número de empregados acima de 3.500 .

Em 1978, esta Portaria sofreu modificaçōes, tomando novo número, Portaria $3214 / 78$ - NR-4, que determinou também a inclusão de 01 Enfermeiro do Trabalho em empresas de saúde com mais de 500 empregados. Este quadro não sofreu mais alterações até o presente momento, em relação à enfermagem.

Em 1985, a OIT promulgou a Resolução $n^{\circ} 171 / 85$ com diretrizes para o atendimento à saúde do trabalhador, estabelecendo nova forma de organização e funcionamento de Serviços de Saúde, excluindo a menção "ocupacional" e fundamentando-se em três princípios básicos: a) Política Nacional de Saúde do Trabalhador essencialmente preventiva; b) Serviços de saúde para todos os trabalhadores, incluindo a setor público, cooperativas de produção e empresas, em função dos riscos prơissionais; c) assistência também aos trabalhadores independentes. As funções destes serviços devem contemplar: vigilância do meio ambiente de trabalho; vigilância da saúde do trabalhador; informação e educação dos trabalhadores em matéria de saúde; formação dos profissionais para atuar neste campo; e assessoria às empresas (1985). Deste modo, o paradigma para formação de especialistas neste campo não pode mais ser o mesmo, e os marcos de referência necessitam, até mesmo por justiça social, contemplar toda a população trabalhadora ativa ou não, no mercado formal ou informal.

De acordo com o que está estabelecido no Art. 200 da Constituição, a saúde é um direito fundamental de todos, e a provisão de condições indispensáveis ao seu pleno exercício é dever do Estado, ficando caracterizadas estas atribuições na Lei $n^{\circ} 8.080 / 90$ - SUS, que prevê a execução de ações de saúde do trabalhador e de colaboração na proteção do meio ambiente incluindo o de trabalho. O Art. $6^{\circ}$ desta Lei atribui à direção nacional do SUS a responsabilidade de coordenar a política nacional de saúde do trabalhador, considerada neste grupo toda a população economicamente ativa, estimada à época em 60 milhões de pessoas (1991). 
Não se trata apenas de cumprir uma Lei, mas a de resgatar o papel que a Saúde Pública já teve no começo da industrialização brasileira, e na sua vocação de tratar da identificação e controle dos riscos e condições de saúde da população, nos diversos grupos populacionais, em todos os niveis de prevenção, e de acordo com a complexidade das intervenções. A própria Constituição Federal também determina ações através do Ministério do Trabalho, que complementam o tratamento das situações específicas de saúde do trabalhador nas empresas e através da seguridade social, formando um complexo multiinstituicional com ações de natureza interministeriais.

A atenção à Saúde é garantida pelo SUS, em consonância com as recomendações da $2^{\mathrm{a}}$ Conferência Nacional de Saúde do Trabalhador (1994), visando contemplar a totalidade dos trabalhadores e compreendendo os seguintes aspectos: a) atendimento por equipes multiprofissionais; b) envolvimento de toda a rede pública de saúde em todos os niveis; c) inclusão das ações de saúde do trabalhador nos diferentes programas de saúde de todas as unidades de saúde; d) funcionamento dos ambulatórios em três turnos; e) atendimento de forma integral com mecanismos de referência e contrareferência para problemas específicos em Centros de Referência, em cada cidade; f) garantia de medicamentos básicos; g) capacitação e treinamento de recursos humanos em saúde do trabalhador; $h$ ) informação e realização de ações educativas para os trabalhadores, conforme preconiza a Recomendação $\mathrm{n}^{\circ} 171 \mathrm{da}$ OIT/85 (1985).

Quanto à atuação do Enfermeiro do Trabalho no Programa de Saúde do Trabalhador, não há uma exigência formal de Curso de Enfermagem do Trabalho; contudo, a $2^{\text {a }}$ Conferência Nacional de Saúde do Trabalhador (1994) recomenda formação de natureza multidisciplinar em Saúde do Trabalhador com disciplinas consideradas usualmente como especialidades, especialmente para o pessoal que atua na rede de serviços. Orienta ainda a implementação da Portaria 678 de 14/05/91, do Ministério da Educação, que recomenda nos currículos, entre outros, os seguintes conteúdos: a) Prevenção do uso indevido de substâncias psicoativas; b) Educação ambiental; c) Educação no Trânsito; d) Educação do consumidor; e) Prevenção das DSTIAIDS; f) Prevenção de Acidentes de Trabalho; g) Defesa Civil; h) Relação Contribuinte/Estado; e i) Educação em Saúde (1994).

Diante deste panorama, questiona-se:

- Qual o paradigma que deve direcionar a formação do Especialista em Enfermagem do Trabalho no Brasil ?

- Em que se deve basear o seu Marco Referencial ?

Tendo como base as inúmeras alterações políticas, sociais e de saúde do trabalhador no Brasil, pretende-se, com este trabalho, identificar os Marcos Conceitual, Referencial e Metodológico na formação da Especialidade de Enfermagem do Trabalho, e tendências da atuação do enfermeiro no serviço de saúde do trabalhador. 


\section{FORMAÇÃO DO ENFERMEIRO DO TRABALHO NO BRASIL}

\section{Pós-Graduação no Brasil: Necessidade de Aperfeiçoamento Profissional}

A pós-graduação brasileira emergiu como conseqüência do processo de desenvolvimento econômico e social, que reclamava um espaço institucional onde pudesse gerar ciência e tecnologia, expandindo-se rapidamente na década de 70 . Hoje pode-se afirmar que grande parte da tecnologia e da ciência brasileira é gerada na pós-graduação.

A pós-graduação em enfermagem surgiu com os cursos de aperfeiçoamento e/ou especialização, e tinha por objetivo qualificar docentes e avançar no conhecimento de enfermagem. A produção científica desses cursos veio permitir um avanço e uma visão critica da qualidade da assistência de enfermagem, bem como situar a profissão no setor da saúde e na sociedade, evidenciando os determinantes da prática profissional. Contudo, muitos são os obstáculos que se opõe ao aproveitamento deste avanço nos serviços de saúde, como é o caso da Enfermagem do Trabalho.

\section{Histórico da Especialização em Enfermagem do Trabalho}

A percepção de Enfermagem do Trabalho como "especialidade" ocorre inicialmente de forma mais clara e definida entre 1972 e 1975, com base na Resolução $n^{\circ}$ 112/54 da OIT/MS, embora a constatação da necessidade se dê em 1969, quando, no Congresso Mundial da Saúde e Segurança do Trabalho, a OIT organizou um Seminário sobre Formação de Enfermeiros do Trabalho. Enquanto a maioria dos representantes (enfermeiras dos diversos paises participantes) relatavam suas experiências em formação, definição de funções e regulamentação da enfermagem do trabalho nas empresas, lamentavelmente, para nós, o Brasil se fez representar por um médico, que compareceu para dizer que não tinha experiência em treinar Enfermeiros do Trabalho porque o país sequer dispunha de uma legislação que obrigasse as empresas a manter serviços de saúde ocupacional, conforme citação no texto "PROPOSTA DE CURSO DE ESPECIALIZAÇÃO À NIVEL DE PÓS-GRADUAÇÃO "LATUSENSO" (ANENT, 1979).

A realidade da situação, até 1972, era: auxiliares de enfermagem, freqüentemente treinados pelos médicos nas próprias empresas, realizando por iniciativa própria ou por sugestão de seus chefes, pequenas cirurgias, com suturas inclusive, sem que estivessem legal e profissionalmente capacitados para esse exercício. Esta realidade era pouco sentida pela classe de profissionais, uma vez que a enfermagem do trabalho se realizava no âmbito das empresas onde a comunicação com os órgãos de classe é limitada; por conseguinte, as intervenções neste sentido custaram a ser executadas. Somente algumas enfermeiras de indústria do Rio de Janeiro, justamente as que contavam, à época, mais de cinco anos de experiência em serviços de saúde ocupacional, foram as primeiras que reconheceram a necessidade de formação especializada. 
A presença de enfermeiros nas empresas, mesmo nas situações em que a lei não obrigava sua inclusão na equipe de saúde ocupacional, se deu pela sensibilidade de alguns empresários, que conseguiram valorizar a melhoria da qualidade do atendimento prestado ao seus empregados, e conseqüente aumento de nível de satisfação, e diminuição dos acidentes e/ou doenças ocupacionais.

Quanto à absorção do Enfermeiro do Trabalho, qualquer que seja o grau de risco ocupacional, a legislação brasileira prevê apenas e somente um Enfermeiro do Trabalho para as empresas que tenham uma quantidade igual ou superior a 3.501 empregados. Há de se convir que o risco ocupacional não deveria estar vinculado ao número de empregados, uma vez que se há risco de acidentes e/ou doenças profissionais, sem vigilância sanitária adequada, o risco se mantém tanto para 01 como para 1000 empregados. Daí a necessidade de profissionais competentes para desempenhar a tarefa de "vigiar" preventiva-mente riscos de agravos à saúde, em empresas com qualquer número de empregados, e fora dela (empresa).

Outro ponto a ser considerado é a Lei $n^{\circ} 7.458 / 86$ que regulamenta o Exercício Profissional para a Enfermagem, que prevê que as ações do Auxiliar de Enfermagem são todas em nível operacional, auxiliar e, portanto, deverão ser, sempre, supervisionadas por um Enfermeiro. Se tal fato ocorre no nível hospitalar, porque o mesmo não deve ocorrer em Saúde Ocupacional, ou seja, em Saúde do Trabalhador ? Se considerarmos que, em 1984, o número de Enfermeiros do Trabalho era de 01 enfermeiro para 23.022 trabalhadores e que a quantidade e qualidade não têm aumentado muito nestes últimos anos, temos urgência na formação de profissionais competentes e habilitados para diminuir distorções.

Se considerarmos os dados das "Diretrizes do SUS" (1991), o Brasil com uma população de trabalhadores de 60 milhões com as condições de saúde afetadas pelos inúmeros riscos ocupacionais e não ocupacionais, o quantitativo de enfermeiros do trabalho teria que crescer em proporções geométricas; à época, o número de enfermeiras especializadas era de 3000 .

\section{Bases Legais do Curso de Especialização em Enfermagem do Trabalho}

Como já foi mencionado, o Curso de Especialização em Enfermagem do Trabalho iniciou em 1974, sob o controle da FUNDACENTRO - Ministério do Trabalho, que concedia o Registro de Especialista de todos os profissionais para atuarem na Equipe de Saúde Ocupacional, composta de Médicos do Trabalho, Enfermeiro do Trabalho, Engenheiro de Segurança do Trabalho, Inspetor de Segurança e Auxiliar de Enfermagem do Trabalho.

Posteriormente, o Ministério do Trabalho, através da Portaria $n^{\circ} 3.154 / 88$, indicou novas bases para o currículo de formação dos especialistas e condicionou o registro do certificado à FUNDACENTRO, mediante Prova de Avaliação, ao mesmo tempo que desvinculou o curso e o registro dos Engenheiros de Segurança da FUNDACENTRO. Com a Portaria "i Z:,ve, o Ministério do Trabalho passou o registro dos especialistas médicos e 
enfermeiros para os Conselhos Regionais de sua profissão, ficando o enfermeiro com a obrigatoriedade de registro no Conselho Regional de Enfermagem.

No sentido de regulamentar o exercício e os Cursos de Enfermagem do Trabalho, o Conselho Federal de Enfermagem estabeleceu Resoluções que orientaram seu registro e controle em nivel nacional:

- RESOLUÇÃO n 100/88, estabelece que o Curso de Especialização para Enfermeiro deve ter carga horária de 800 horas e que o registro de especialista deve ser solicitado ao Conselho Regional de Enfermagem (COREN);

- RESOLUÇÃO nº 005/90, regulamenta o registro do título de enfermeiro no COREN;

- RESOLUÇÃO n 173/94, substitui a Res. 100/88 e omitiu a exigência de carga horária, reafirmando os procedimentos de registro de Especialista em Enfermagem.

Em nivel de Conselho Federal de Educação, a Resolução $n^{\circ} 12 / 83$ estabelece que a formação de qualquer Especialista fica condicionada a critérios minimos para cursos que possam subsidiar o magistério Superior, considerando os seguintes critérios: (Carga Horária Total mínima - 360 horas; (Incluir matéria sobre Iniciação à Pesquisa; (Conter 60 horas de formação didático-pedagógica; (Freqüência Minima de 85\%; (Aproveitamento Mínimo: grau 7,0; (Corpo Docente qualificado com Titulação de Mestre ou Doutor em pelo menos $3 / 4$ do total de professores.

No Brasil, o primeiro curso para Enfermeira do Trabalho, de acordo com a FUNDACENTRO, previu um currículo com 11 disciplinas e um total de 225 horas; posteriormente foi recomendado pelo COFEN um programa de 800 horas. Nossa experiência levou-nos à realização de uma proposta de programa, em 1995, com 860 horas, progressivamente distribuidas em carga horária teórica, prática, estágio e visitas supervisionadas, visando preparar profissionais capazes de desempenhar atenção de enfermagem ao trabalhador, conhecimentos básicos nas áreas biológicas, psicológicas e social e assegurando as seguintes características:

\section{I-PERFIL PROFISSIONAL E ATRIBUIÇÕES DO ESPECIALISTA EM ENFERMAGEM DO TRABALHO}

- Ser profissional de Enfermagem de nivel superior;

- Estar de acordo com a Classificação Brasileira de Ocupações (CBO), documento oficial do Ministério do Trabalho;

- Ser portador de Certificado de Especialização em Enfermagem do Trabalho;

- Poder enquadrar-se nas normas dos Serviços Especializados em Engenharia de Segurança e Medicina do Trabalho, conforme a Portaria $3.214 / 78$ - NR-4 . 
- Estar classificado pelo COFEN no quadro I, Lei $7.498 / 86$ e Decreto $n^{\circ}$ 94.406/87;

- Estar registrado como Especialista em Enfermagem do Trabalho com base na Resolução 173/94 do COFEN;

- Ter sensibilidade social no que se refere à situação dos trabalhadores;

- Ter interesse para melhorar a qualidade de vida no âmbito do trabalho e familia do trabalhador;

- Ter conhecimento sobre a legislação do trabalho existente no país e convênios internacionais aceitos;

- Demonstrar atitudes e aptidões para desempenhar as funções de enfermagem neste campo, evidenciadas pela capacidade, responsabilidade, espírito de investigação e de luta pela saúde do trabalhador;

- Demonstrar conhecimentos dos aspectos epidemiológicos da saúde ocupacional, da administração, do ensino e da assistência para esta área;

- Demonstrar capacidade de trabalho em equipe e em grupo.

\section{II - ATRIBUICCÓES ESPECÍFICAS DO ESPECIALISTA EM ENFERMAGEM DO TRABALHO}

\section{A - PRIVATIVAMENTE}

- Direção do órgão de enfermagem do trabalho integrante da estrutura básica da instituição ou Serviço de Saúde Ocupacional, de empresa pública e/ou privada, e chefia de serviço e de unidade de enfermagem do trabalho; • Organização e direção dos serviços de enfermagem do trabalho e de suas atividades técnicas e auxiliares, nas empresas prestadoras desse serviço; •Planejamento, organização, coordenação, execução e avaliação dos serviços de atendimento de enfermagem do trabalho; - Coordenação do Serviço de Enfermagem do Trabalho; - Exercício do magistério nas disciplinas especificas dos cursos de enfermagem do trabalho, atendidas as disposições legais relativas ao ensino; • Planejamento, programação e avaliação dos cursos formadores de pessoal de enfermagem do trabalho, atendidas as disposições legais relativas ao ensino; • Composição de comissões julgadoras para exames em disciplinas específicas de Enfermagem do Trabalho, na seleção pessoal, inclusive técnico e auxiliar para cargo e emprego em Serviço de Saúde Ocupacional; - Consultoria, auditoria e emissão de parecer sobre matéria de enfermagem do trabalho; • Consulta de Enfermagem; - Prescrição da assistência de enfermagem do trabalho ; - Cuidados de enfermagem de maior complexidade técnica e que exijam conhecimento de base científica e capacidade de tomar decisão; (Cuidados diretos a trabalhadores em estado grave, com risco de vida. 


\section{B - COMO INTEGRANTE DA EQUIPE DE SAÚDE OCUPACIONAL}

- Participação no planejamento, execução e avaliação dos programas de saúde dos trabalhadores; - Participação na elaboração, execução e avaliação dos planos de saúde ocupacional; • Prescrição de medicamentos estabelecidos em programas de saúde ocupacional e em rotina aprovada pelo serviço; -Participação nos programas de identificação, avaliação e controle de riscos ocupacionais em empresas ou comunidade; - Participação no planejamento, programação e avaliação dos cursos formadores de recursos humanos em H.S.T., obedecidas as disposições legais relativas ao ensino;

\section{III - OBJETIVOS, MARCOS E ESTRUTURAS PROGRAMÁTICAS DO CURSO} OBJETIVOS

- Propiciar ao enfermeiro conhecimentos, habilidades e atitudes para atuar nas áreas de saúde e trabalho, visando o desenvolvimento de ações específicas tais como: - atender necessidades de saúde do trabalhador relacionadas com o trabalho, ou que tenham repercussão na familia e na comunidade; - organizar e desenvolver programas de educação para a saúde dando ênfase à promoção e recuperação da saúde, prevenção dos agravos em relação ao ambiente de trabalho e adaptação do trabalho ao trabalhador; • prestar assessoria técnica às empresas, à equipe, aos sindicatos e outras instituições; - aplicar o método científico no estudo de problemas de saúde do trabalhador e do meio-ambiente, investigando as relações com o trabalho e possiveis soluções; - integrar a equipe de saúde multidisciplinar atuando no planejamento, organização, execução e avaliação das atividades desenvolvidas; - atuar no ensino de conhecimentos específicos de Enfermagem do Trabalho.

\section{MARCO CONCEITUAL}

De acordo com QUEIROZ (1986), a assistência à saúde do trabalhador requer uma discussão e uniformização de conceitos básicos para dar suporte para essa prática assistencial. Assim, conceitos como trabalho saúde do trabalhador e enfermagem do trabalho deverão ser definidos, tendo como referência o contexto das relações sociais e do trabalho do País. Assim sendo, a assistência à saúde do trabalhador requer, então, uma prática assistencial, inserida no contexto das relações sociais de uma coletividade, em um determinado momento histórico, visando a melhoria das condições de saúde, de trabalho e de vida desses trabalhadores e conseqüentemente dessa coletividade" Queiroz (1986).

Esse conceito representa a forma de assumir que a saúde do trabalhador não pode estar desvinculada da análise das condições reais de vida e trabalho, e que são elas, em última instância, as determinantes do processo saúde/doença do trabalhador.

Ao se situar a prática assistencial, em um determinado momento, reforça-se a necessidade de considerar as condições reais de vida e de trabalho em constante mutação, vinculando-as à situação sócio-econômica-sanitária e de 
trabalho existentes em uma dada fase de desenvolvimento das relações do capital e trabalho. Admite-se, assim, o inter-relacionamento entre vida, trabalho e saúde, dentro de uma estrutura onde se desenvolvem as relações entre capital e trabalho.

"Neste contexto, a enfermagem do trabalho será conceituada como sendo "uma especialidade da enfermagem geral, com um conjunto de conhecimentos e de prática, visando assistir o trabalhador ou grupo de trabalhadores, situando-o no contexto de saúde, de trabalho e de vida num determinado momento histórico, com a finalidade de promover, manter ou recuperar sua saúde, e com isso, a melhoria dessas condiçōes" (Queiroz, 1986).

Para exercer a enfermagem do trabalho, o enfermeiro deverá assumir um real compromisso com o trabalhador, envolvendo-o no diagnóstico e na busca de soluçöes dos problemas, identificando, estimulando e promovendo condições concretas para que o conjunto de trabalhadores tome consciência da relação existente entre vida, trabalho e saúde e que, em conjunto com os profissionais da saúde, procure a identificação e solução desses problemas.

\section{MARCO REFERENCIAL}

O marco conceitual baseia-se nos conceitos de trabalho e saúde como um processo dinâmico em relação aos riscos aos quais estão expostos os trabalhadores, no processo produtivo e no meio ambiente, em relação às atividades primárias, secundárias e terciárias de produção.

A atenção à saúde é de natureza multiprofissional e o Enfermeiro do Trabalho é partícipe do programa de atenção. A politica de saúde do trabalhador é resultante do programa inter-institucional (Saúde, Trabalho, Previdência) com apoio da Educação e da política econômica do País. Hoje, a referência deste marco é a Lei $8.080 / 90$-SUS e a Portaria 3.214/78/NR-4, até que esta seja modificada. A atenção de saúde se baseia nos princípios da eqüidade e universalidade, tendo como porta de entrada o serviço público e as empresas.

\section{MARCO METODOLÓGICO}

O processo ensino-aprendizagem é dinâmico devendo o aluno obter uma compreensão critica da realidade. A competência é adquirida pelo saber teórico e pela prática profissional de conteúdos específicos das ciências sociais e humanas. A compreensão crítica se dá pela inserção do enfermeiro em equipe, vivenciando a realidade do trabalhador e a atuação do aluno refletindo as açōes de enfermagem. O aluno é agente de sua aprendizagem e o professor tem o papel de facilitador encaminhando, identificando e solucionando os problemas identificados. 


\section{ESTRUTURA PROGRAMÁTICA (ANEXO 1)}

O programa é constituído de três Áreas com Módulos e Disciplinas correspondentes e experiências didático-pedagógicas, a saber:

ÁREA I ( Domínio Conexo - Inclui disciplinas cujo conteúdo tem conexão com outras matérias que constituem a área de saber de um profissional especialista;

- ÁREA II ( Domínio Especifico - Inclui disciplinas cujo conteúdo é próprio e/ou relativo à saúde do trabalhador, abrangendo a organização e o processo de trabalho, os riscos relativos (físicos, químicos, biológicos e ergonômicos) às medidas de proteção, controle e tratamento do problemas e à legislação pertinente. Inclui também os pressupostos teóricos e metodológicos do atendimento à saúde do trabalhador pelo enfermeiro e sua participação na equipe multidisciplinar;

- ÁREA III ( Aplicacão Específica - Envolve o desempenho dos estudantes na prática assistencial nos âmbitos de enfermagem do trabalho, na pesquisa, no processo administrativo e no ensino, com base nos fundamentos científicos das disciplinas.

\section{CRITÉRIOS PARA AVALIAÇÃO}

Avaliação do processo ensino-aprendizagem baseia-se nas seguintes matérias:

- Freqüência nas aulas teóricas - $85 \%$;

- Freqüência nas aulas práticas - $90 \%$;

- Avaliação do rendimento estabelecida pelo professor;

- Exigência de uma Monografia realizada com base em pesquisa bibliográfica ou pesquisa de campo, visando a explicação de um problema específico de saúde do trabalhador e possiveis indicações de solução com a participação do enfermeiro;

- Diagnóstico da situação, Plano e Trabalho, Execução e Relatório de Avaliação de Experiências em Campo;

- A participação do aluno é fundamental.

Os resultados serão conceituados como: A - graus 10,0 a 9,0 (Excelente/Aprovado) ; B - 8,9 a 8,0 (Bom / Aprovado) ; C - 7,9 a 7,0 (Regular / Aprovado); D - menos de 7,0 (Deficiente/ Reprovado). 


\section{CONCLUSÃO}

A proposta do Curso de Especialização para Enfermeiro do Trabalho, ao longo dos 21 anos de experiência na Escola de Enfermagem Ana Nery, dez dos quais sob a Coordenação desta autora, veio sofrendo modificações visando o seu aperfeiçoamento e sua adequação aos momentos históricos das políticas que fundamentaram os programas de Saúde do Trabalhador no Brasil.

Começou com um marco referencial voltado para o trabalhador na indústria e a assistência se relacionava com a atenção preferencialmente voltada para prevenção de Acidentes no Trabalho - HIGIENE INDUSTRIAL ; posteriormente, o marco referencial vinculou-se à saúde do trabalhador em relação à sua ocupação - SAÚDE OCUPACIONAL - cuja assistência à saúde do trabalhador estava sob a égide do Ministério do Trabalho. A partir da Reforma Sanitária na década de 80 , o marco referencial passa pela correlação capital e trabalho, e neste contexto o problema do trabalhador extrapola os limites da empresa, e se projeta na vida deste de forma global. Refere-se à saúde de todos os trabalhadores, mesmo daqueles que, por circunstâncias adversas, se encontram em situação de desemprego, e/ou em condições de saúde precária, decorrente da doença que teve origem no trabalho. Tem-se como apoio a premissa da saúde integral e o marco conceitual da saúde do trabalhador, onde o trabalho é apenas um dos determinantes do processo saúde/doença.

Nesta filosofia, o trabalhador brasileiro deve ser o sujeito e agente da atenção considerado tanto pelo Ministério do Trabalho quanto pelos Ministérios da Saúde e o da Previdência Social. Assim sendo, o MARCO REFERENCIAL para formar Enfermeiros do Trabalho no contexto atual brasileiro deve contemplar uma proposta curricular inserida no sistema hierarquizado de assistência, passando pela saúde global, até chegar ao nível de especialização. Deve preconizar a formação de profissionais com senso crítico e competência para prestar assistência de enfermagem do trabalho a trabalhadores sadios e doentes, administrar serviços de enfermagem na empresa ou no serviço público - Centro de Saúde do Trabalhador (CET) ou Centro de Referência à Saúde do Trabalhador (CRST), e realizar pesquisa e ensino de enfermagem do trabalho. Em conjunto com a equipe multi-profissional, identificar, avaliar e controlar os riscos à saúde do trabalhador no meio ambiente de trabalho e/ou na comunidade onde vivem.

O MARCO CONCEITUAL DO CURSO DE ESPECIALIZAÇÃO EM ENFERMAGEM DO TRABALHO deve ser assegurado com base nos conceitos de saúde integral à saúde do trabalhador e na assistência holística de enfermagem. 
ANEXO 1 PROGRAMA ANALÍTICO

\begin{tabular}{|c|c|c|c|}
\hline $\begin{array}{c}\text { Área do } \\
\text { Conhecimento }\end{array}$ & Módulos & CHT & Disciplinas \\
\hline \multirow[t]{2}{*}{ 1- Domínio Conexo } & Metodologia da Pesquisa & 90 & $\begin{array}{l}\text { Metodologia da Pesquisa Cientifica Aplicada } \\
\text { Elaboraçăo da Monografia }\end{array}$ \\
\hline & Didática Aplicada & 45 & $\begin{array}{l}\text { Metodologia do Ensino da Enfermagem e } \\
\text { Educação na Área da Saúde }\end{array}$ \\
\hline \multirow[t]{5}{*}{ II- Dominio Especifico } & $\begin{array}{l}\text { O Trabalhador e a } \\
\text { Empresa }\end{array}$ & 90 & $\begin{array}{l}\text { - Saúde e Trabalho: histórico e conceituação } \\
\text { - Sociologia do Trabalho } \\
\text { - Psicologia do Trabalho } \\
\text { - Ergonomia Aplicada a Saúde do Trabalhador } \\
\text { - Organizaçấo de serviço de Saúde do } \\
\text { Trabalhador } \\
\text { - Informática Aplicada }\end{array}$ \\
\hline & $\begin{array}{l}\text { Diretrizes Políticas e } \\
\text { Legislação Especifica do } \\
\text { Trabalho e da } \\
\text { Enfermagem do Trabalho }\end{array}$ & 90 & $\begin{array}{l}\text { - Diretrizes Politicas Internacionais e Nacionais } \\
\text { - OIT, OMS, Constituiçăo, SUS } \\
\text { - Legislaçăo do Trabalho - CLT, Acidentes de } \\
\text { Trabalho, Normas Regulamentadoras } \\
\text { - Ética e Deontologia de Enfermagem } \\
\text { - Legislaçăo do Exercício e do Ensino de } \\
\text { Enfermagem do Trabalho }\end{array}$ \\
\hline & Ambiente e Trabalho & 95 & $\begin{array}{l}\text { - Higiene do Trabalho } \\
\text { - Segurança no Trabalho } \\
\text { - Saneamento Básico e Industrial } \\
\text { - Estudo de Riscos no Trabalho }\end{array}$ \\
\hline & Saúde e Trabalho & 135 & $\begin{array}{l}\text { - Epidemiologia em Saúde do Trabalhador } \\
\text { - Estatistica Aplicada } \\
\text { - Fisiologia do Trabalho } \\
\text { - Doenças Profissionais e do Trabalho }\end{array}$ \\
\hline & $\begin{array}{l}\text { Saúde do Trabalhador e a } \\
\text { Enfermagem }\end{array}$ & 105 & $\begin{array}{l}\text { - Histórico da Enfermagem do Trabalho no } \\
\text { Mundo e no Brasil e Conceituaçăo } \\
\text { - Fundamentos Teóricos da Enfermagem do } \\
\text { Trabalho } \\
\text { - Metodologia da Assistência de Enfermagem } \\
\text { - Organização dos Serviços } \\
\text { - Procedimentos Especificos em Saúde } \\
\text { Ocupacional } \\
\text { - Primeiros Socorros no Trabalho } \\
\text { - Educaçăo em Saúde }\end{array}$ \\
\hline $\begin{array}{l}\text { III-Aplicação } \\
\text { Especifica }\end{array}$ & $\begin{array}{l}\text { Enfermagem do Trabalho } \\
\text { na Empresa }\end{array}$ & 210 & $\begin{array}{l}\text { - Diagnóstico Situacional de Enfermagem na } \\
\text { Empresa } \\
\text { - Visitas Técnicas e Relatórios } \\
\text { - Estágio Supervisionado } \\
\text { - Estudos de caso }\end{array}$ \\
\hline TOTAL & & 860 & \\
\hline
\end{tabular}




\section{BIBLIOGRAFIA}

1. ABEn, Associação Nacional de Enfermeiros. Relatório das Atividades da Comissão de Educação. Período de jun./74 a maio/75.

2. ANENT, Associação Nacional de Enfermeiros do Trabalho. Proposta de Curso de Especialização em Enfermagem do Trabalho à nível de Pós-graduação "Lato-sensu"- Estatuto. Anent, 1979

3. BRASIL . Constituição Federativa do Brasil, 1988.

4. BRASIL, MINISTÉRIO DA SAÚDE. Relatório da $7^{a}$ Conferência Nacional de Saúde do Trabalhador. Brasília, DF, 1986.

5.

Relatório da $2^{a}$ Conferência Nacional de Saúde do Trabalhador. Conselho Nacional de Saúde, Brasilia, DF, 1986.

6. Nacional de Saúde. Brasília, DF, 1986.

Relatório da $8^{a}$ Conferência . Lei $n^{\circ} 8.080 / 90$.

8. BRASIL, MINISTÉRIO DA SAUUDE / SNVS - Divisão de Proteção à Saúde do Trabalhador. Saúde do Trabalhador: Diretrizes de Ação para o SUS. Brasília, DF, 1991.

9. BRASIL, MINISTÉRIO DO TRABALHO. Portaria n 3.237 de 1972.

10. BRASIL, MINISTÉRIO DO TRABALHO. Legislação do Programa de Valorização do Trabalho. Rev. Bras. Saúde Ocupacional, 1 (1): 1-80, jan./fev./mar, 1973.

11. BRASIL, MINISTÉRIO DO TRABALHO E PREVIDËNCIA SOCIAL Departamento Nacional de Segurança do Trabalho - Programa Nacional de Valorização do Trabalhador, PNVT, CANPAT. Brasil, D.O. de $26 / 07 / 72$.

12. MANUAIS DE LEGISLAÇÃO - ATLAS. Segurança e Medicina do Trabalho, $n^{\circ} 16$. Lei No 6.514/77. Ed. Atlas S.A., 26a ed., 1994.

13. MAURO, M.Y.C. et CORDEIRO, D.S. Na História de Enfermagem, a tenacidade e uns cria a especialidade de outros. Resenha Histórica. $O$ Jornal Brasileiro de Enfermagem. Rio de Janeiro, Cidade Ed. Científica, n. 91,92,96,97. Ano 1988.

14. OIT/OMS. Recomendação n० $112 / 59$.

15. OIT. Recomendação no 171/85.

16. QUEIROZ, V.M. Organização de Serviços de Enfermagem do Trabalho (Dissertação de Mestrado) - USP. São Paulo, 1977.

17. SÃO PAULO - Boletim de Saúde do Trabalhador - Construindo uma Política de Saúde do Trabalhador, Programa de Saúde do Trabalhador. SP , jun./1994. 